\title{
Cement Materials Based on Cellulosic Fibers for Plasters
}

\author{
Viola Hospodarova ${ }^{1}$, Nadezda Stevulova ${ }^{1}$, Jozef Junak ${ }^{1}$, Anton Geffert ${ }^{2}$, Frantisek \\ Kacik $^{2}$, Jaroslav Briancin ${ }^{3}$ \\ ${ }^{1}$ Technical University of Košice, Slovakia \\ Faculty of Civil Engineering, Institute of Environmental Engineering \\ ${ }^{2}$ Technical University in Zvolen, Slovakia \\ Faculty of Wood Sciences and Technology, Department of Chemistry and Chemical Technologies \\ ${ }^{3}$ Institute of Geotechnics SAS, Slovak Academy of Science, Kosice, Slovakia \\ e-mail: viola.hospodarova@tuke.sk, nadezda.stevulova@tuke.sk,jozef.junak@tuke.sk, \\ geffert@tuzvo.sk,kacik@tuzvo.sk,briancin@saske.sk
}

\begin{abstract}
This paper presents physical and mechanical properties of cementitious composites/plasters containing cellulosic fibers in portion $2.0 \%$ and $5.0 \%$ of filler replacement after 28 days of hardening. Cellulosic fibers (Greencel) originated from bleached wood pulp and unbleached waste paper used in this experimental work were characterized from the point of view cellulose structure. Experimental investigations reveal that adding cellulosic fibers reduces composites density (up to $8.2 \%$ ) in comparison with composites without any fibers. Moreover, the presence of wood pulp and recycled fibers in composites cause higher values of water absorbability than sample without fibers. Also, the decrease in compressive strength values for tested fiber cement plasters was observed (14.1 - 18.0 MPa) in comparison to reference sample (26.6 MPa). But the identified compressive strength values are in accordance with European standard (5 MPa) for plasters.
\end{abstract}

Key words: wood pulp, waste paper, cellulosic fibers, cement composites, density, water absorbability, compressive strength

\section{Introduction}

The utilization of plant fibers, as a fast renewable and biodegradable source, in building materials is dated from long before. A mix of straw and clay were used as materials for construction purpose in ancient Egypt and China. However, an upward interest was recorded on use natural fibers for the application to cement based composites in last three decades, considering the increasing environmental fears and awareness of industrial pollution $[1,2,3]$. The increasing interest is in the use of natural fibers especially as the reinforcing material in composites with inorganic or organic matrix because of their availability, low weight, renewability, and satisfactory mechanical properties. Composites reinforced with natural ligno/cellulosic fibers are used in application such as automotive interior parts, construction, and packaging [4]. Natural cellulosic fibers such as cotton, hemp, jute, flax, ramie, sisal, 
bagasse, specialty fibers processed from wood, agricultural waste and etc., available for concrete and cementitious materials as reinforcement (significant enhancement in the properties of cementitious materials). These fibers are obtained from renewable resources and are readily available at relatively low cost compared to man-made fibers. The advantages of utilization of natural fibers as a raw material for cement composites are tremendous in terms of environmental, energy and resource conservation [5]. The research results indicated that the addition of cellulosic fibers can improve physical and mechanical properties of cementitious materials. The density reduction, the increase in the flexural strength [6], control of the initiation and growth of micro-cracks [7], and improvement of the impact resistance [8] composites based on cellulosic fibers were recorded. Cement composites reinforced by natural fibers are most suitable for foundation floor for machinery in factories, fabrication of light weight cement based roofing and ceiling boards, wall plaster, and construction materials for low-cost housing [9]. The factors influencing the physical and mechanical properties of natural fibers reinforced cement composites can be divided into three major categories. The first one is the type and characteristics of reinforcing fibers. The second and third important factors are the nature of the cement base matrix (and mix design) and the way of mixing, casting and curing of these composites respectively. One of the most dominating factors influencing the mechanical properties of fiber-cement composites is a homogeneous distribution of the reinforcing fibers in the cement matrix [10]. Agricultural waste fibers are widely available in most countries and can be used as suitable materials for brittle cement matrix reinforcement. Taking into account the excellent mechanical properties of fibers, with a suitable mix design, it is possible to develop a material with appropriate properties for building purposes [11]. Recently, the sustainable development policies have drawn the attention on researchers for implementation of waste materials and fibers to the production of building materials [12]. In the work [13], there has been used industrial waste as a secondary raw material in restoration plaster where were tested its physical, mechanical and thermal properties. Behavior of cement composite using wastepaper fibers has been investigated and compared to fiber-cement composites manufactured with virgin wood cellulose fibers [12]. The accessibility of non-commercial fibrous wastes also supports their potential utilization throughout sustainable methods of production of building components [14].

This paper presents characteristics of cellulosic fibers and physical and mechanical properties of cement composites/plasters with $2.0 \%$ and $5.0 \%$ of filler replacement by cellulosic fibers. The aim of this experimental work is to review the influence of filler amount replaced by fibers on physical and mechanical properties of 28 days hardened cement composites/plasters.

\section{Materials and Methods}

\subsection{Materials}

In this study was used an ordinary Portland cement CEM I 42.5 N (Cement factory Ladce, Slovakia) in accordance with European standart STN EN 196-1 [15]. Natural silica sand in fraction 0-1 $\mathrm{mm}$ and tap water were used. Six types of cellulosic fibers, three from grey recycled waste paper fibers and three from bleached wood pulp (white), were supplied by company Greencel Ltd (Hencovce, Slovakia). 


\subsection{Preparation of specimens and methods of testing}

Control plaster and fiber-cement plasters are made by using the same formulation but 2.0 and $5.0 \mathrm{wt}$. \% of sand substituted cellulosic fibers. The mix proportion of cement specimens were designed with Cement/Sand (C/S) weight ratio of 1:3 and Water/Cement (W/C) ratio of 0.75. Preparation of fiber reinforced cement composites was carried out in two steps. The first, the cellulose pulp was dispersed in water by mechanical stirring (approximately $50 \mathrm{wt} \%$ of water); and the second, cement, sand and remaining amount of water were added, and mixing continues to allow uniform fiber dispersion in the mixture. Standard prismatic specimens of size $40 \times 40 \times 160 \mathrm{~mm}$ were prepared. The marks of composite specimens with recycled waste paper fibers G-500T, G-700T and G-3/00T are RPA, RPB and RPC; for specimens with wood pulp fibers G250WT, GW500 and W640 are WPA, WPB and WPC; and for reference sample is RF, respectively.

The bodies were cured and removed from the molds after 2 days and specimens were held under PVC foil for their hardening under laboratory conditions at $20 \pm 2{ }^{\circ} \mathrm{C}$ and $50 \pm 5 \% \mathrm{RH}$ next 26 days. Density, water absorbability, compressive strength of composites after 28 days of hardening were determined in accordance with standard STN EN 1015-10 [16], STN 731316 [17] and STN EN 1015-11 [18]. Strength parameter testing was performed by using the instrument ADR 2000 (ELE International, England). Three bodies of each composite were prepared for measurements of properties.

\section{Results}

\subsection{Characterization of cellulosic fibers}

The SEM images of selected representative samples of two cellulosic fibers types are shown in Fig.1. The important characteristics of samples are given in Table 1. As is shown, cellulosic fibers from recycled waste paper fibers contain lower cellulose amount than those from bleached wood pulp. Bulk density is changing from 30 to $100 \mathrm{~kg} / \mathrm{m}^{3}$. Aspect ratio as of an elemental fiber describing the proportional relationship between its length and its diameter is ranging from 18.8 to 30 .

Table 1: Properties of Greencel cellulosic fibers

\begin{tabular}{|c|c|c|c|c|c|c|c|}
\hline $\begin{array}{c}\text { Cellulose } \\
\text { fibers } \\
\text { sample }\end{array}$ & $\begin{array}{c}\text { Cellulose } \\
\text { content } \\
{[\%]}\end{array}$ & $\begin{array}{c}\text { Bulk } \\
\text { density } \\
{\left[\mathrm{kg} / \mathrm{m}^{3}\right]}\end{array}$ & $\begin{array}{c}\text { Max. } \\
\text { length } \\
{[\mu \mathrm{m}]}\end{array}$ & $\begin{array}{c}\text { Dry } \\
\text { matter } \\
{[\%]}\end{array}$ & $\begin{array}{c}\text { Ash } \\
{[\%]}\end{array}$ & $\mathrm{pH}$ & $\begin{array}{c}\text { Aspect } \\
\text { ratio } \\
\text { L/d }\end{array}$ \\
\hline G-500T & 80 & $50-100$ & 400 & 93 & 20 & $7 \pm 1$ & 18.8 \\
\hline G-700T & 80 & $40-70$ & 600 & 93 & 20 & $7 \pm 1$ & 22.7 \\
\hline G-3/00T & 80 & $30-50$ & 1200 & 93 & 20 & $7.5 \pm 1$ & 27.5 \\
\hline G 250WT & 80 & $80-100$ & 500 & 93 & 20 & $7 \pm 1$ & 23.6 \\
\hline GW-500 & 99.5 & $60-80$ & 500 & 93 & 0.5 & $6 \pm 1$ & 23.2 \\
\hline W 640 & 99.5 & $35-45$ & 1000 & 93 & 0.5 & $6 \pm 1$ & 30 \\
\hline
\end{tabular}



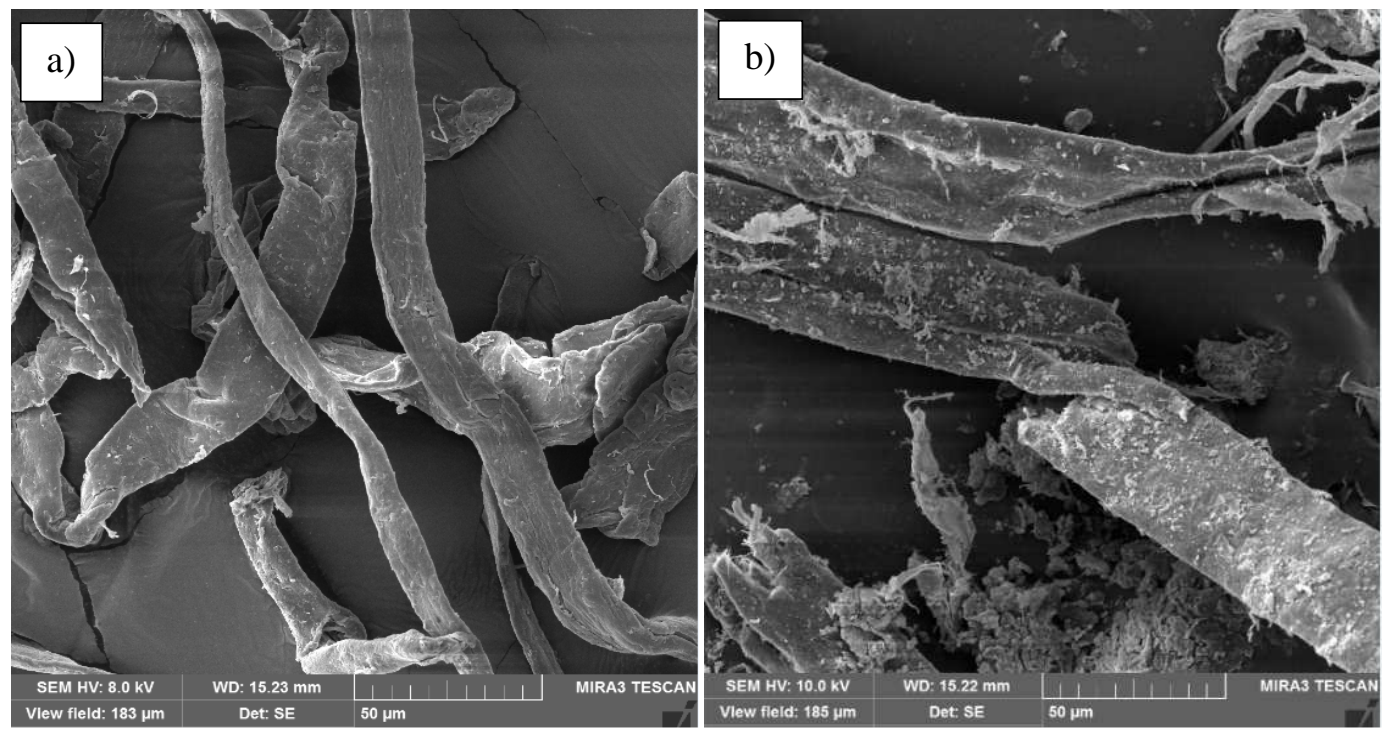

Figure 1: SEM micrographs of wood pulp fibers (a) and waste paper fibers (b) at magnification 1500 times

The attention was focusing on determining the important structural parameter - degree of polymerization (DP) of cellulose that varies according to its sources, acquiring processes and further treatments. Structural changes in cellulose having a significant effect on its mechanical properties were studied by the method of size exclusion chromatography (SEC). This method allows the determination of the average cellulose chain length, measured as degree of polymerization (DP). Table 2 displays values of DP, important molecular parameters such as molecular weight values ( $\mathrm{Mn}$ and $\mathrm{Mw}$ ) and polydispersity index (PDI) of cellulose from different sources namely from recycled waste paper and wood pulp. Recycled waste paper fibers have slightly higher values of degree of polymerization than wood pulp fibers. Cellulose molecular weight distributions (MWD) of the representative cellulosic fibers samples constructed from chromatograms are shown in Figs. 2a and 2b. As it can be seen, the distribution is bimodal and value of PDI calculated by dividing Mw by Mn is ranging of 6.16 to 6.92 .

Table 2: The resulting values of weight-average molecular weight (Mw), number-average molecular weight (Mn), polydispersity index (PDI) and degree of polymerization of cellulose (DP) for waste paper fiber and wood pulp samples

\begin{tabular}{|c|c|c|c|c|c|}
\hline \multicolumn{2}{|c|}{ Cellulosic sample } & Mw & Mn & PDI & DP \\
\hline \multirow{3}{*}{$\begin{array}{c}\text { Waste paper } \\
\text { fibre }\end{array}$} & G-500T & 190,475 & 27,637 & 6.92 & 1,176 \\
\cline { 2 - 6 } & G-700T & 192,747 & 31,276 & 6.16 & 1,190 \\
\cline { 2 - 6 } & G-3/00T & 208,100 & 33,045 & 6.30 & 1,285 \\
\hline \multirow{3}{*}{ Wood pulp } & G250WT & 184,006 & 27,840 & 6.61 & 1,136 \\
\cline { 2 - 6 } & GW500 & 175,642 & 26,233 & 6.70 & 1,084 \\
\cline { 2 - 6 } & W640 & 181,164 & 26,731 & 6.78 & 1,118 \\
\hline
\end{tabular}




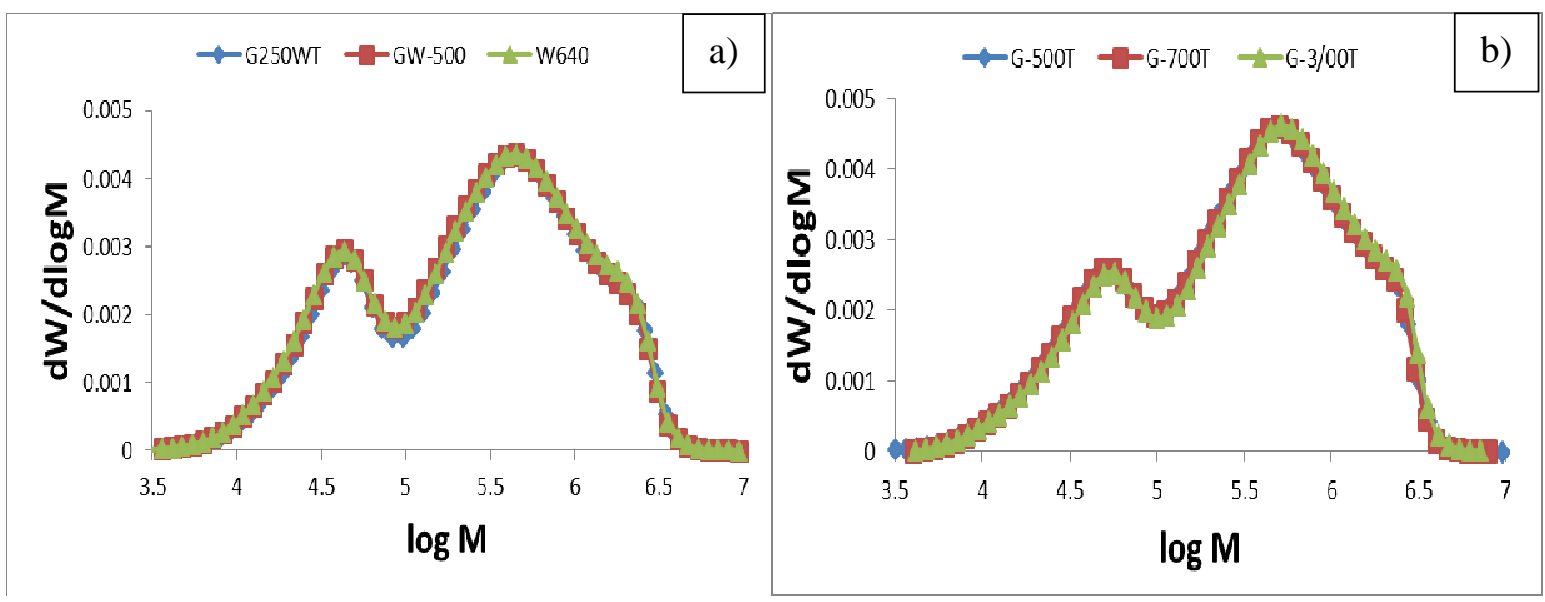

Figure 2: Cellulose molecular weight distribution of wood pulp (a) and waste paper fibers (b)

\subsection{Characterization of composite properties}

The density values of fiber-cement plasters with $2 \%$ and $5 \%$ of cellulosic fiber contents shown in Fig.3 ranged $1904-1987 \mathrm{~kg} / \mathrm{m}^{3}$. For the plasters with $2 \%$ of filler replacement by fibers, reduction in density is in the range $4.2 \%-7.2 \%$, however, decrease in density values for composites with $5 \%$ fibers amount is higher $(5.5 \%-8.2 \%)$. The highest changes in density (7.3 and $8.2 \%$ ) were recorded for composites RPA (with $5 \%$ of recycled paper) and WPB (with $5 \%$ of wood pulp), respectively. This fact relates to incorporation of cellulosic fibers having low density what causes the decrease in densities of fiber-cement composites, in keeping with presented studies [19].

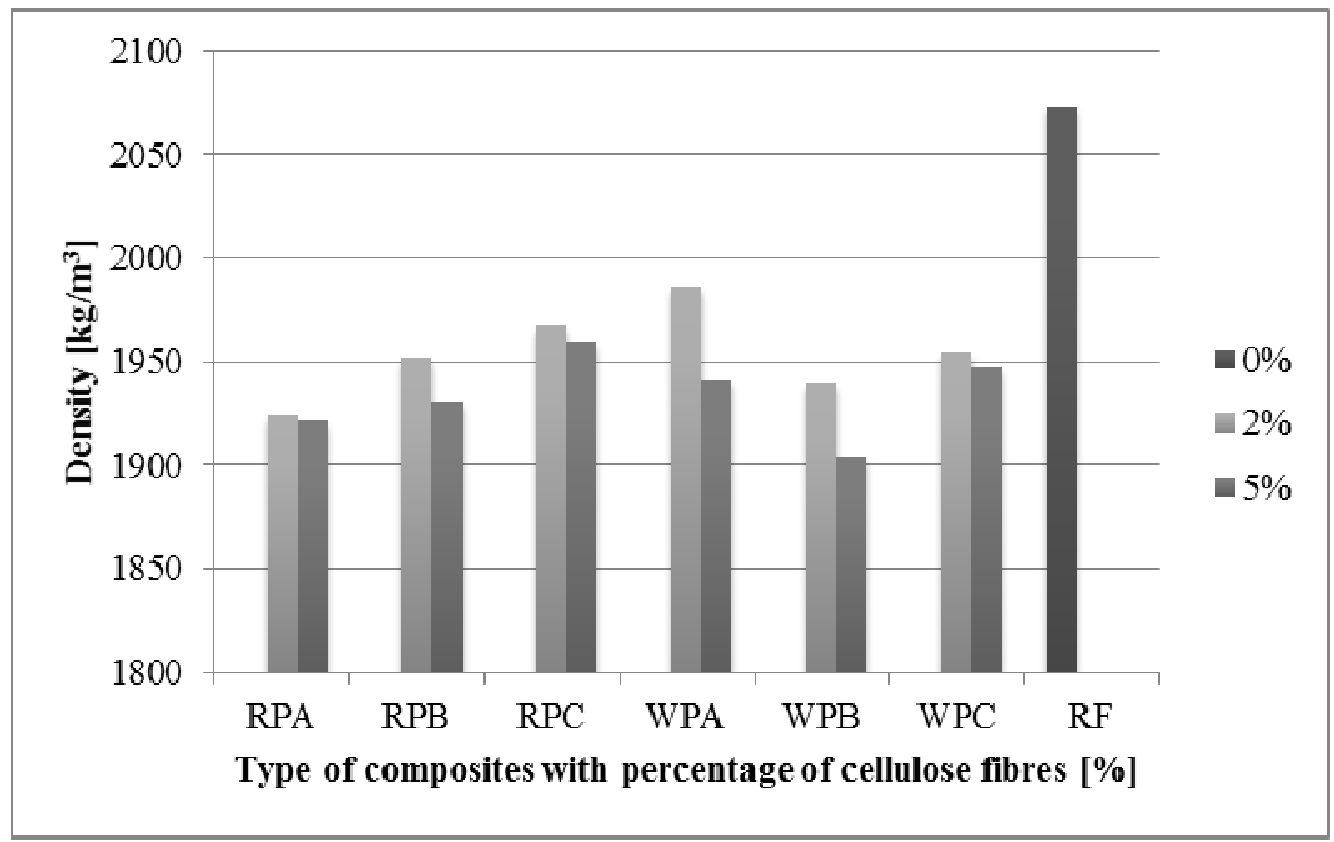

Figure 3: Density of fiber-cement plasters with $2 \%$ and $5 \%$ of cellulosic fiber contents 
Cellulosic fibers have hydrophilic nature, and this attribute is causing an increase in water absorption of fiber-cement composites. The results (Fig.4) show an increase in water absorbability of cement composites with rising amount of cellulosic fibers in composites in accordance with published work [19]. Plasters reinforced with $2 \%$ and $5 \%$ cellulosic fibers reached water content in the range $12.2 \%-13.5 \%$.

Water absorbability values of composites with wood pulp were higher than water absorbability of cement composites based on waste paper. The maximal increase in water absorbability was observed in specimens WPB and RPB with $5 \%$ fibers (13.5\% and $12.9 \%)$.

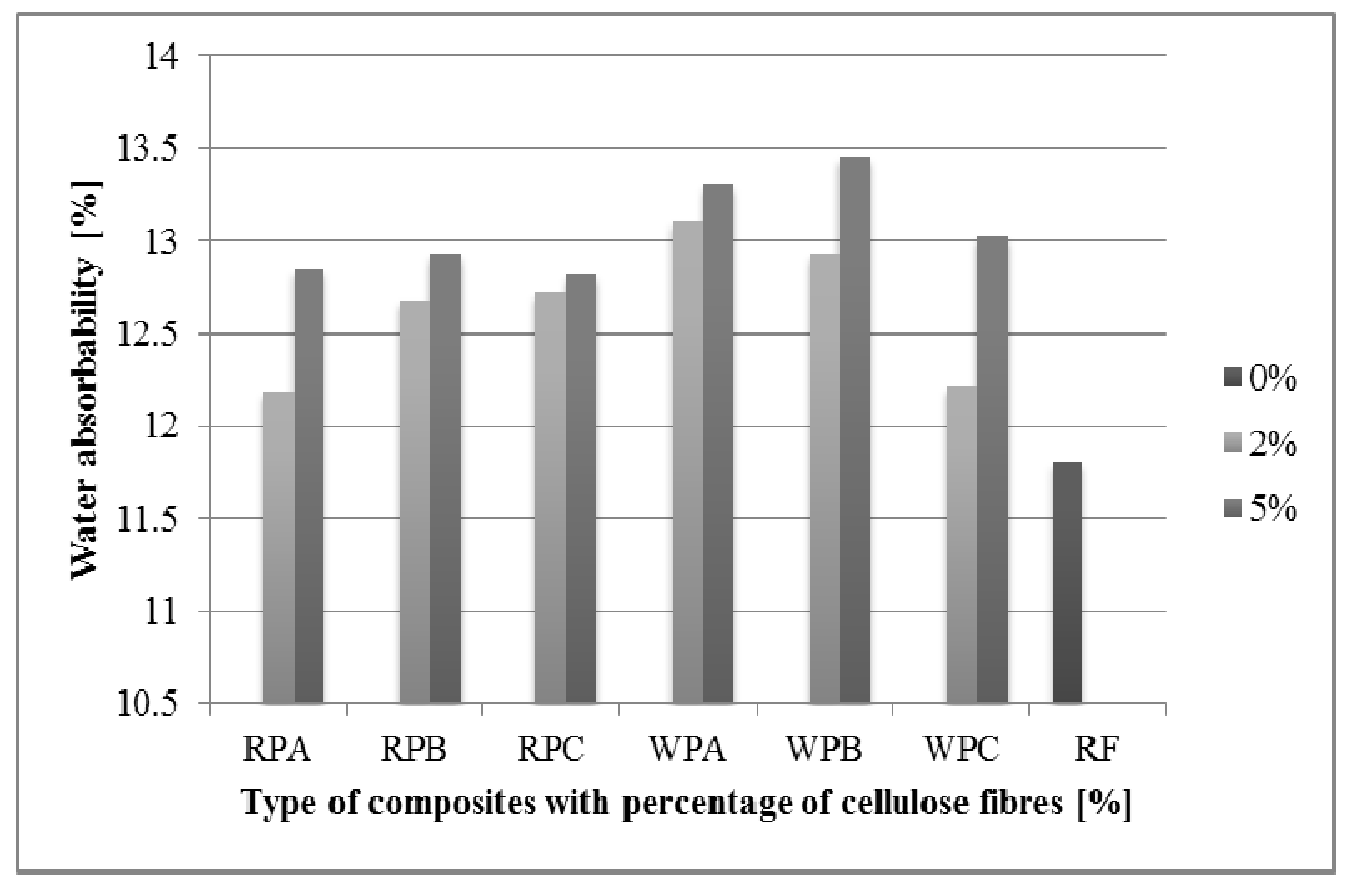

Figure 4: Water absorbability values of composites based on $2 \%$ and $5 \%$ fiber content of wood pulp and recycled paper

The effect of both types of cellulosic fibers in $2 \%$ and $5 \%$ portion on compressive strengths of fiber cement specimens after 28 days of hardening is shown in Fig.5. Comparison of compressive strength values of reference sample without fibers $(26.6 \mathrm{MPa})$ and specimens containing $2 \%$ and 5\% of cellulosic fibers (recycled paper and wood pulp) showed significant decrease in compressive strength $(32.3 \%$ - $46.9 \%)$. However, slight differences were observed in compressive strength of fiber cement composites containing 2 and $5 \%$ cellulosic fibers. Specimens WPC (5\% wood pulp), RPC ( $2 \%$ waste paper) and RPA ( $2 \%$ and 5\%) waste paper show the highest compressive strength values ranged about 17.3-18.0 MPa. Accordance with European standard STN EN 998-1; the minimum compressive strength required for cement mortars for plastering is $5 \mathrm{MPa}$ [20].

The strength of the bond between cellulosic fibers (waste paper fibers and wood pulp) and cement matrix determines the composite properties and depends on properties of filler and binder. Some of the important parameters having an impact on interface interaction and the overall durability of the composite are the matrix composition, binder particle size 
distribution, fiber characteristics such as its geometry, type, orientation, surface characteristics and volume portion [21].

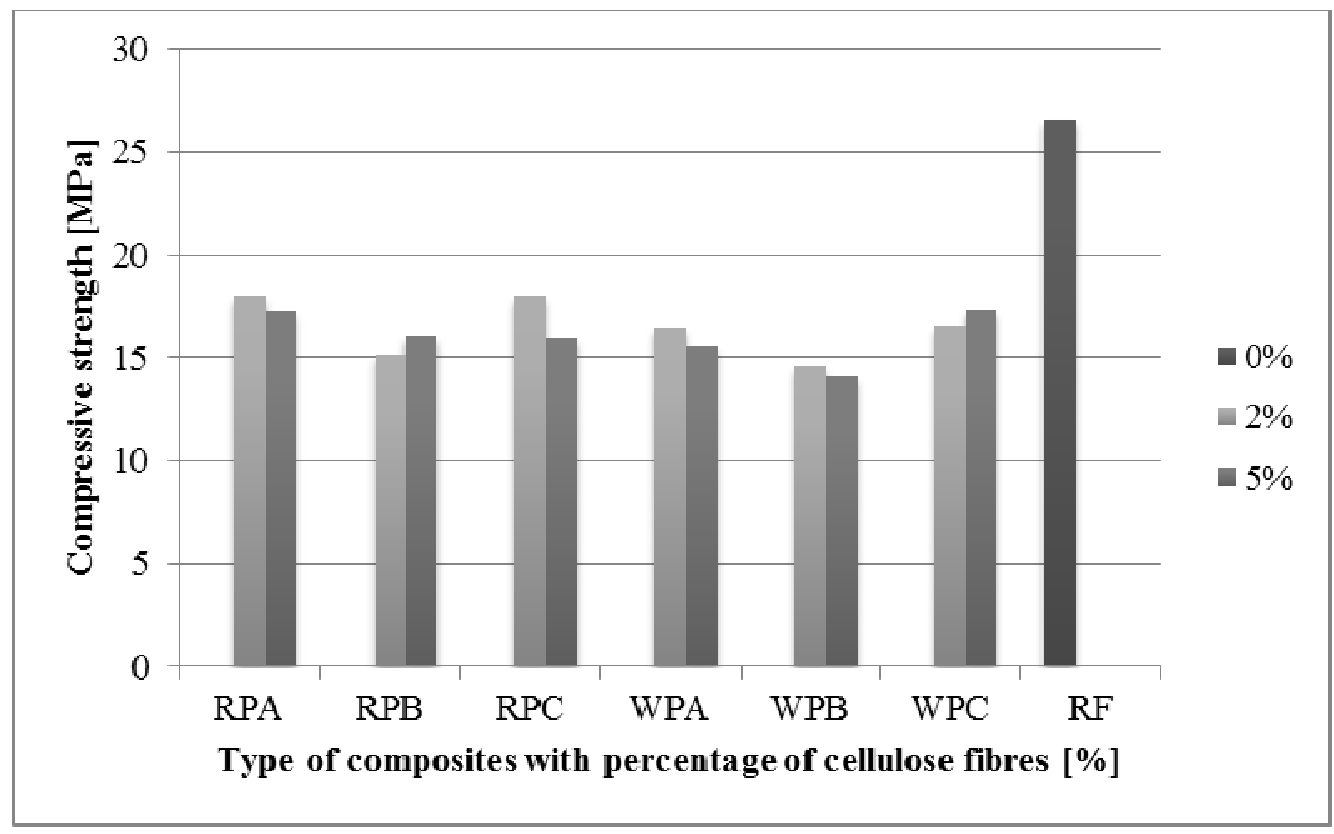

Figure 5: The effect of cellulosic fibers on the compressive strength of fiber-cement plasters

Generally, the higher molecular weight of a polymer causes its higher mechanical strength [22]. But it has been found that strength properties decrease with decreasing degree of polymerization of the cellulose [23] because structural changes in cellulose have an effect on the mechanical properties of cellulosic fibers.

Dependence of cellulose degree of polymerization on resulting values of compressive strength of fiber cement composites is shown in Fig.6. Based on relatively large scattering of the compressive strength values of 28 days hardened composites in dependence on degree of polymerization of used cellulosic materials, structural parameter of cellulosic fibers (DP) has no visible impact of fibers parameter on the mechanical properties of the fiber cement composites. Probably, there are several reasons associated with distribution of fibers in matrix, surface properties of cellulosic fibers and their adhesion to cement particles. 


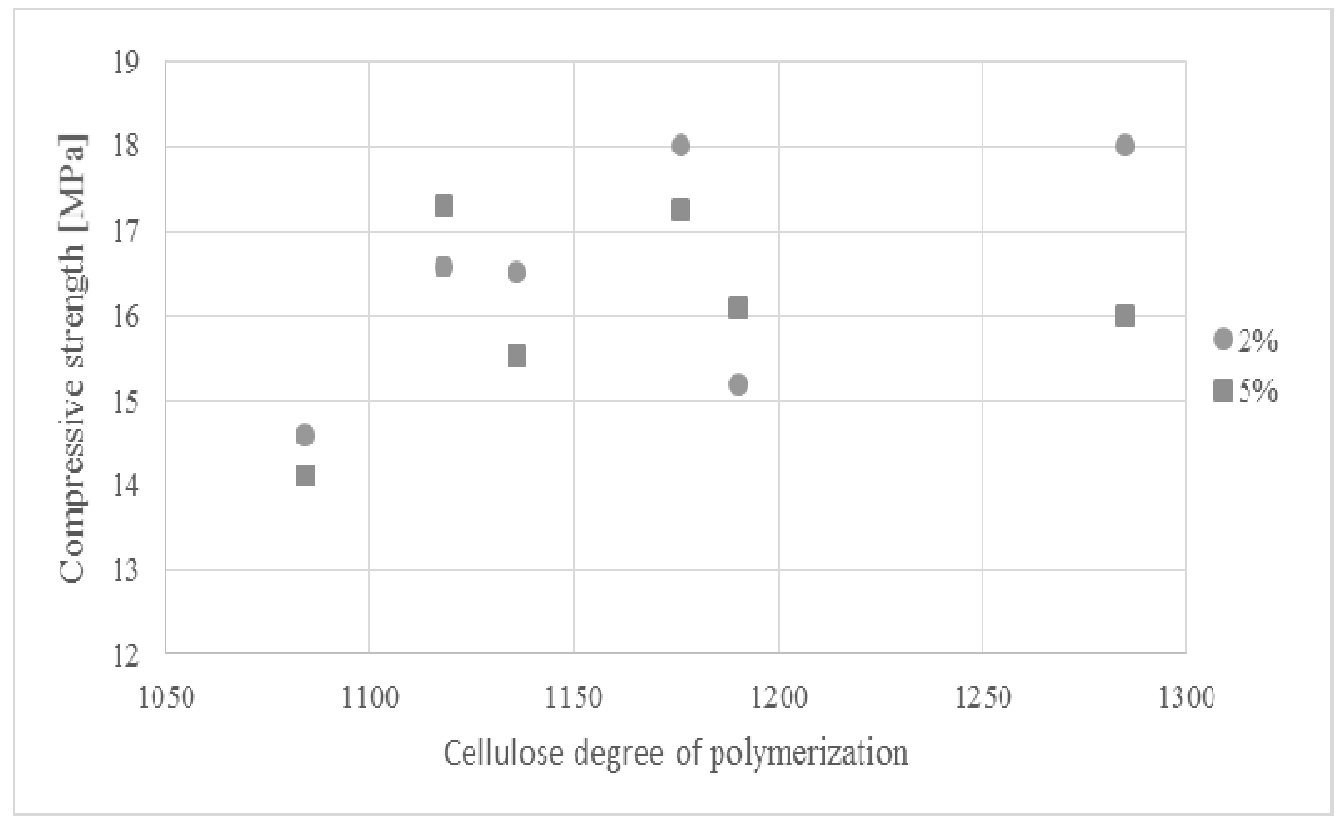

Figure 6: Dependence of cellulose degree of polymerization on resulting values of compressive strength of fiber cement composites

\section{Conclusion}

In this paper, characterization of cellulosic fibers of various quality (recycled waste fibers and wood pulp fibers) and the effect of partial filler replacement $(2 \%$ and $5 \%)$ in cement materials based on cellulosic fibers for plasters is presented. Small differences in structural parameter of cellulose were observed. The physical and mechanical properties such as density, water absorbability and compressive strength of fiber cement composites after 28 days of hardening were studied. Composites manufactured with cellulosic fibers are lighter in weight while the water absorbability increases of fiber cement composites when compared to reference sample. Compressive strength values of both fiber cement samples ranging from 14.1 to $18.0 \mathrm{MPa}$. The results of testing showed that density, water absorbability and compressive strength of the fiber cement composites are influenced by the amount and characteristics of cellulosic fiber.

\section{Acknowledgements}

The authors are grateful to the Slovak Scientific Grant Agency for financial support of the project VEGA 1/0277/15.

\section{References}

[1] Xie, X., Gou, G., Wei, X., Zhou, Z., Jiang, M., Xu, X., Wang, Z. \& Hui, D. (2016). Influence of pretreatment of rice straw on hydration of straw fiber filled cement based composites. Construction and Building Materials, 113, 449-455. 
[2] Chakraborty, S., Kundu, S. P., Roy, A., Basak, R. K., Adhikari, B., \& Majumder, S. B. (2013). Improvement of the mechanical properties of jute fibre reinforced cement mortar: a statistical approach. Construction and Building Materials, 38, 776-784.

[3] Wei, J., \& Meyer, C. (2015). Degradation mechanisms of natural fiber in the matrix of cement composites. Cement and Concrete Research, 73, 1-16.

[4] JA, M. H., Majid, M. A., Afendi, M., Marzuki, H. F. A., Hilmi, E. A., Fahmi, I., \& Gibson, A. G. (2016). Effects of water absorption on Napier grass fibre/polyester composites. Composite Structures, 144, 138-146.

[5] Onuaguluchi, O., \& Banthia, N. (2016). Plant-based natural fibre reinforced cement composites: A review. Cement and Concrete Composites, 68, 96-108.

[6] Khorami, M., \& Ganjian, E. (2011). Comparing flexural behaviour of fibre-cement composites reinforced bagasse: wheat and eucalyptus. Construction and Building Materials, 25(9), 36613667.

[7] Tonoli, G. H. D., Belgacem, M. N., Siqueira, G., Bras, J., Savastano, H., \& Lahr, F. R. (2013). Processing and dimensional changes of cement based composites reinforced with surfacetreated cellulose fibres. Cement and Concrete Composites, 37, 68-75.

[8] Ramakrishna, G., \& Sundararajan, T. (2005). Impact strength of a few natural fibre reinforced cement mortar slabs: a comparative study. Cement and concrete composites, 27(5), 547-553.

[9] Chakraborty, S., Kundu, S. P., Roy, A., Basak, R. K., Adhikari, B., \& Majumder, S. B. (2013). Improvement of the mechanical properties of jute fibre reinforced cement mortar: a statistical approach. Construction and Building Materials, 38, 776-784.

[10] Jarabo, R., Fuente, E., Monte, M. C., Savastano, H., Mutjé, P., \& Negro, C. (2012). Use of cellulose fibers from hemp core in fiber-cement production. Effect on flocculation, retention, drainage and product properties. Industrial Crops and Products, 39, 89-96.

[11] Khorami, M., \& Ganjian, E. (2011). Comparing flexural behaviour of fibre-cement composites reinforced bagasse: wheat and eucalyptus. Construction and Building Materials, 25(9), 36613667.

[12] Khorami, M., \& Ganjian, E. (2013). The effect of limestone powder, silica fume and fibre content on flexural behaviour of cement composite reinforced by waste Kraft pulp. Construction and Building Materials, 46, 142-149.

[13] Václavík, V., Daxner, J., Valíček, J., Dvorský, T., Kušnerová, M., Harničárová, M., Bendová, M. \& Břenek, A. (2014). The use of industrial waste as a secondary raw material in restoration plaster with thermal insulating effect. In Advanced Materials Research (Vol. 897, pp. 204-214). Trans Tech Publications.

[14] Savastano, H., Warden, P. G., \& Coutts, R. S. (2003). Potential of alternative fibre cements as building materials for developing areas. Cement and Concrete composites, 25(6), 585-592.

[15] Slovak Office of Standards, Metrology and Testing. (2016). Methods of testing cement - Part 1: Determination of strength. STN EN 196-1. Slovakia.

[16] Slovak Office of Standards, Metrology and Testing. (2001). Methods of test for mortar for masonry. Part 10: Determination of dry bulk density of hardened mortar. STN EN 1015-10. Slovakia.

[17] Slovak Office of Standards, Metrology and Testing. (1989). Determination of moisture content, absorptivity and capillarity of concrete. STN 73 1316. Slovakia. 
[18] Slovak Office of Standards, Metrology and Testing. (2001). Methods of test for mortar for masonry. Part 11: Determination of flexural and compressive strength of hardened mortar. STN EN 1015-11. Slovakia.

[19] Savastano, H., Warden, P. G., \& Coutts, R. S. P. (2000). Brazilian waste fibres as reinforcement for cement-based composites. Cement and Concrete Composites, 22(5), 379-384.

[20] Slovak Office of Standards, Metrology and Testing. (2011).Specification for mortar for masonry. Part 1: Rendering and plastering mortar. STN EN 998-1. Slovakia.

[21] Pehanich, J. L., Blankenhorn, P. R., \& Silsbee, M. R. (2004). Wood fiber surface treatment level effects on selected mechanical properties of wood fiber-cement composites. Cement and Concrete Research, 34(1), 59-65.

[22] Shezad, O., Khan, S., Khan, T., \& Park, J. K. (2010). Physicochemical and mechanical characterization of bacterial cellulose produced with an excellent productivity in static conditions using a simple fed-batch cultivation strategy. Carbohydrate Polymers, 82(1), 173180 .

[23] Zimmermann, T., Bordeanu, N., \& Strub, E. (2010). Properties of nanofibrillated cellulose from different raw materials and its reinforcement potential. Carbohydrate Polymers, 79(4), 10861093. 